\title{
Influences of soil properties and stem density on the growth and inner bark biomass of paper mulberry (Broussonetia papyrifera) in natural stands, Thailand
}

\author{
Maliwan Tanasombat $^{1)}$, Katsutoshi SAKURAi ${ }^{1)}$, Songkram Thammincha ${ }^{2)}$ and Bunvong ThaiUtSa ${ }^{2)}$ \\ ${ }^{1)}$ Faculty of Agriculture, Kochi University, Nankoku, Kochi 783-8502, Japan; \\ ${ }^{2)}$ Faculty of Forestry, Kasetsart University, Chatuchak, Bangkok 10900, Thailand
}

\begin{abstract}
Natural stands of paper mulberry are the main source of raw material for paper mulberry manufacturing. Stand improvement is needed for proper growth and high yield. Three $5 \times 10 \mathrm{~m}$ sample plots $\left(50 \mathrm{~m}^{2}\right)$ of different tree and stem density (low, medium and high density as Plot A, B and C, respectively) were set on Mae Charim district, Nan province, and Wang chin district, Phrae province, Thailand, which are famous for paper mulberry production. Within all plots, soil properties, crown closure, growth and biomass were investigated. In this study, stem density correlated to inner bark biomass; soil fertility and light intensity also contributed to growth enhancement. As for soil nutrients, available phosphorus showed a significant correlation to paper mulberry growth. Although paper mulberry in the Wang chin site had a higher average stem density after the first harvesting than paper mulberry in the Mae Charim site, the former site resulted in a lower inner bark yield that may have been caused by low soil fertility and smaller number of stems in the 1.5 - 3.5 cm DBH class (economical stems) than those in the Mae Charim site, except in plot C.. In both study sites and the two annual harvesting periods, inner bark biomass in Plot $\mathrm{C}$ was the highest followed by those in Plot B and then A. . Therefore, among sites with similar soil fertility (site quality), increasing stem density resulted in higher inner bark yield. Applying fertilizer and maintaining $2-3$ stems $\mathrm{m}^{-2}$ is recommended for paper mulberry stands in Thailand.
\end{abstract}

Key words: soil property, stem density, growth, biomass, paper mulberry, natural stand

\section{INTRODUCTION}

Paper mulberry, a medium-height tree (10-15 m) of the Moraceae family, has been utilized as raw material for paper making for many years. Besides papermaking, paper mulberry can also be used as a herb or for clothing. In Thailand, paper mulberry, Broussonetia papyrifera (L.) Vent, is a fast growing pioneer species (Phengklai \& Khamsai, 1985; Matthew, 1990). It is also found naturally in almost all regions, especially along rivers and on fertile soils with high moisture and sufficient sunlight. This plant can be propagated by using either the coppice or stolon (Mongkolsook et al., 2001). At present, $60 \%$ of paper mulberry bark used in papermaking is obtained from natural stands, and $40 \%$ from mixed plantations (Thammincha, 2001; Udomchoke et al., 2001). Therefore, the quantity and quality of the inner bark of paper mulberry are not consistent due to the limited areas for paper mulberry stands and poor management (Thammincha, 2001). Furthermore, demand for bast fiber has increased due to increased paper manufacturing and the failure of paper mulberry plantations leading to supply shortages of paper mulberry fiber. These failures may have been caused by insufficient management at the beginning of planting (seedling stage) resulting in high competition with other weeds for light and soil nutrients, consequently lowering the survival rate, making the plantations unprofitable. To satisfy the increased demand, proper management and harvesting processes for paper mulberry in natural stands by increasing the growth rate and inner bark biomass of paper mulberry, is needed. To enhance stand productivity, use of optimal tree density and a suitable amount of soil nutrients are crucial. A study on Ailanthus triphysa showed high biomass yield in the high density stands (Shujauddin \& Kumar, 2003), however these stands also had a greater accumulation of N, P and K, with a higher potential for nutrient export through harvest. Soil fertility plays an important role in obtaining optimal stand yields (Laatsch, 1954). Many species such as Pinus taeda (Adegbidi et al., 2002), Gmelina arborea (Onyekwelu, 2004), and Fraxinus excelsior (Kerr \& Cahalan, 2004) provided greater biomass in soils with higher fertility. Among the key factors that affect tree growth in natural stands, light is a dominating factor in many ecosystems (Brunner, 1998) especially for paper mulberry, which is a light-demanding species. According to Ford (1982), the tree crown could have a major effect on tree growth. The crown system couples tree functioning with atmospheric conditions, because the structural properties of the crown, which effect light interception are influenced by atmospheric conditions (Kellomaki \& Strandman, 1995). The importance of light was confirmed with the significant correlation between total height and the square root of crown surface in Quercus ilex stands that were affected by shading 
(Gracia \& Retana, 2004). Therefore, the relationship between crown structure and stand growth increment was investigated to understand stand dynamics (Le Goff et al., 1995; Ottorini et al., 1996; Le Goff \& Ottorini, 1996). This study aims to enhance the quality and quantity of paper mulberry bast fiber by recommending effective management for paper mulberry in natural stands.

\section{MATERIALS AND METHODS}

\section{The study site}

There were two study sites: one was set in Mae Charim district, Nan province and the other was set in Wang chin district, Phrae province, both in Northern Thailand. Mae Charim district is located in a mountainous area about $480 \mathrm{~m}$ a.s.1.. Between 1998 and 1999, the average temperature, relative humidity and average annual precipitation was $26.7{ }^{\circ} \mathrm{C}, 76.0 \%$ and $1,279 \mathrm{~mm}$, respectively. Wang chin district is located on a flat basin, $160 \mathrm{~m}$ a.s.l. with an average temperature, relative humidity and average annual precipitation similar to Mae Charim district: $26.8{ }^{\circ} \mathrm{C}, 73.7 \%$ and 1,228 mm, respectively. Mae Charim soil was classified as Aquic Paleustalfs. This soil type is known to leach bases and erode easily. Paleustalfs occur in relatively stable landscapes; their slopes are mostly gently. Most of the soils are used as cropland or for grazing (USDA, 1999). In Thailand, these soils were determined to have medium to high fertility, however the degree of slope should be considered before utilizing the land to obtain an optimum productivity (Land Development Department, 1991). Soil at Wang chin site was classified as Lithic Eutrudepts, which are soils with minimal development, formed mainly from more loamy and clayey parent materials. Udepts have well-drained characteristics, however a low to medium level of soil fertility is common in these soils. Therefore, they can be utilized for crop cultivation in gently sloping areas, but on steep slopes, pastures or fast growing species plantations are recommended (Land Development Department, 1991; USDA, 1999).

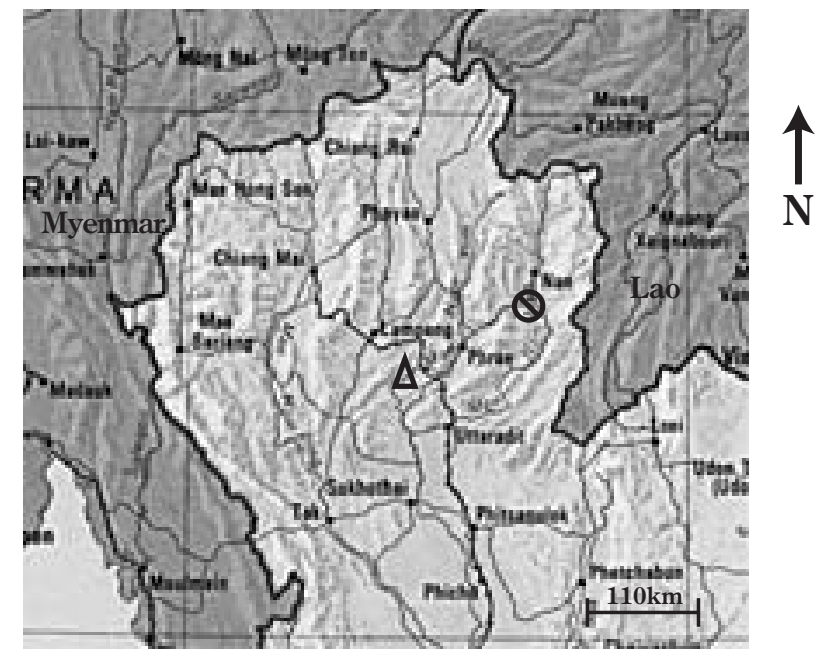

Fig. 1. Locations of two study sites of natural stands of paper mulberry

Notes: $\boldsymbol{Q}=$ Mae Charim site, Nan province, $\boldsymbol{\Delta}$ = Wang chin site, Phrae province

Table 1. Locations of natural stands of paper mulberry

\begin{tabular}{ccccccccc}
\hline District & Province & Latitude & Longitude & $\begin{array}{c}\text { Elevation } \\
(\mathrm{m} \text { a.s.l.) }\end{array}$ & $\begin{array}{c}\text { Average } \\
\text { Temperature* } \\
\left({ }^{\circ} \mathrm{C}\right)\end{array}$ & $\begin{array}{c}\text { Relative } \\
\text { Humidity* } \\
(\%)\end{array}$ & $\begin{array}{c}\text { Annual } \\
\text { Precipitation* } \\
(\mathrm{mm})\end{array}$ & $\begin{array}{c}\text { Soil } \\
\text { Type** }\end{array}$ \\
\hline MC & Nan & $20^{\circ} 66^{\prime} 273^{\prime \prime} \mathrm{N}$ & $69^{\circ} 27^{\prime} 10^{\prime \prime} \mathrm{E}$ & 480 & 26.7 & 76 & 1,279 & Agric-Palenstalfs \\
WC & Phrae & $1^{\circ} 65^{\prime} 415^{\prime \prime} \mathrm{N}$ & $57^{\circ} 57^{\prime} 85^{\prime \prime} \mathrm{E}$ & 160 & 26.8 & 73.7 & 1,228 & Lithic-Entrudepts \\
\hline
\end{tabular}

Notes: * = Data from the Meteorology department, 1998-1999

$* *=$ Data from USDA-NRCS, 2000 


\section{Plot establishment}

The study sites were selected in Mae Charim district, Nan province and Wang chin district, Phrae province in Northern Thailand, which are famous places for paper mulberry bast fiber production. Three $5 \mathrm{x} 10 \mathrm{~m}$ sample plots $\left(50 \mathrm{~m}^{2}\right)$ of different plant density (low, medium and high density as Plot A, B and C, respectively) were set on each site. Because the natural stand does not cover a wide area, we could not set a replication at each site.

\section{Growth measurement and analysis}

Growth measurement in terms of total height $(\mathrm{H})$ and diameter at breast height (DBH) of all plants in every plot were measured before harvest as the first measurement (M1), 3 and 6 months after harvest as the second (M2) and third measurement (M3), respectively. Then paper mulberry plants in all plots were harvested and the inner bark biomass taken in this harvesting period was recorded as the second harvesting. For biomass analysis, twenty plants in each plot were harvested randomly. The harvested plants were divided into twigs, leaves, inner bark, outer bark, and core stems, then weighted separately. Sub-samples were taken from each part to be oven-dried at $80^{\circ} \mathrm{C}$ for at least 48 hours to obtain the wet to dry ratio.

\section{Soil analysis}

Disturbed soil samples (three pits, six samples from each plot) were collected for analysis of both physical and chemical properties. Soil was taken at two depths, 0-5 and 20-40 cm, for the surface and subsurface soil samples from each pit. The $\mathrm{pH}$ value was measured with a $\mathrm{pH}$ meter using a soil solution ratio of 1:5 after shaking for 1 hour. The amount of organic matter (OM) was determined by Walkley-Black titration (Walkley \& Black, 1934). Soil samples were extracted twice with 1 Mammonium acetate at pH 7 (Peech, 1945; Pratt, 1965) and exchangeable cations (Ca, Mg and $\mathrm{K}$ ) were determined using an atomic absorption spectrophotometer (AA). Available phosphorus content (P), was measured with the Bray II Method (Bray \& Kurtz, 1945), where soil samples were extracted with an extracting solution (1 N NH4F and $0.5 \mathrm{~N} \mathrm{HCl})$ then a color developing reagent was added and available $\mathrm{P}$ was determined by absorbance measurement with a spectrophotometer at 710 nm. Soil texture was analyzed with the pipette method (Kilmer \& Alexander, 1949; Day, 1965).

\section{Statistic analysis}

Data from both sites were analyzed for differences in growth and yield. ANOVA was used to test overall differences and further correlation analyses were made using Pearson's method at 0.05 and 0.01 significance levels.

\section{RESULTS AND DISCUSSION}

\section{Soil properties}

Soil properties of the three plots at the Mae Charim site were not significantly different. Soil texture in Plot A was sandy clay loam (SCL), while those in Plot B and C were clay loam (CL). The pH of the three plots were between 6.5 and 6.8. Soil in Plot A had the highest content of organic matter $\left(62 \mathrm{~g} \mathrm{~kg}^{-1}\right), \mathrm{P}\left(53.0 \mathrm{mg} \mathrm{kg}^{-1}\right)$ and $\mathrm{K}\left(0.90 \mathrm{cmol}^{(+)} \mathrm{kg}^{-1}\right)$. At Plot $\mathrm{C}$, the amounts of exchangeable $\mathrm{Ca}$ and $\mathrm{Mg}$ were the highest $\left(7.92\right.$ and $\left.0.94 \mathrm{cmol}(+) \mathrm{kg}^{-1}\right)$, while $\mathrm{P}$ and $\mathrm{K}$ were the lowest $(11.6 \mathrm{mg}$ $\mathrm{kg}^{-1}$ and $0.51 \mathrm{cmol}(+) \mathrm{kg}^{-1}$, respectively). Among the soil chemical properties at the Mae Charim site, high values of available phosphorus and some exchangeable bases may have resulted from the parent material; previously the land had been utilized as a para rubber plantation for eight years, and may have also been affected by fertilizers applied to the adjacent orchard on the upper slope.

Soil texture at the Wang chin site was loam in Plot A and B, and clay loam in Plot C. Soil pH in the three plots were not much different, ranging from 6.5 to 7.2. Soil organic matter in Plot A was highest with $49 \mathrm{~g} \mathrm{~kg}^{-1}$, while Plot B and C had 21 and $36 \mathrm{~g} \mathrm{~kg}^{-1}$, respectively. Plot $\mathrm{C}$ had the highest amount of $\mathrm{P}, \mathrm{K}, \mathrm{Ca}$ and $\mathrm{Mg} ; 5.0 \mathrm{mg} \mathrm{kg}{ }^{-1}, 0.74,2.46$ and $0.52 \mathrm{cmol}^{(+)} \mathrm{kg}^{-1}$, respectively, while the differences in the concentrations of those minerals in Plot A and Plot B were not significant at the 0.05 significance level. Soil properties in both sites are shown in Table 2.

\section{Crown projection diagrams}

In the Mae Charim district, the paper mulberry stands were selected along the creeks. The stand age was 4 years old and annual harvesting by villagers was done without any management. Plot A, B and C were set depending on the density of 
Table 2. Soil properties in Mae Charim and Wang chin site

\begin{tabular}{|c|c|c|c|c|c|c|}
\hline \multirow{2}{*}{ Soil properties } & \multicolumn{3}{|c|}{ Mae Charim site } & \multicolumn{3}{|c|}{ Wang chin site } \\
\hline & Plot A & Plot B & Plot C & Plot A & Plot B & Plot C \\
\hline $\mathrm{pH}\left(\right.$ soil : $\left.\mathrm{H}_{2} \mathrm{O}=1: 5\right)$ & 6.6 & 6.8 & 6.5 & 7.0 & 6.5 & 7.2 \\
\hline Organic matter $\left(\mathrm{g} \mathrm{kg}^{-1}\right)$ & 62 & 47 & 45 & 49 & 21 & 36 \\
\hline Available P (mg kg $\left.{ }^{-1}\right)$ & 53.0 & 16.6 & 11.6 & 3.9 & 3.5 & 5.0 \\
\hline Exchangeable $\mathrm{K} \quad\left(\mathrm{cmol}(+) \mathrm{kg}^{-1}\right)$ & 0.90 & 0.66 & 0.51 & 0.38 & 0.33 & 0.74 \\
\hline Exchangeable $\mathrm{Ca}\left(\mathrm{cmol}(+) \mathrm{kg}^{-1}\right)$ & 3.52 & 2.82 & 7.92 & 2.11 & 1.62 & 2.46 \\
\hline Exchangeable $\mathrm{Mg}\left(\mathrm{cmol}(+) \mathrm{kg}^{-1}\right)$ & 0.92 & 0.77 & 0.94 & 0.42 & 0.27 & 0.52 \\
\hline \multicolumn{7}{|l|}{ Soil Texture } \\
\hline Sand $(\%)$ & 51 & 29 & 37 & 35 & 45 & 43 \\
\hline Silt $(\%)$ & 25 & 35 & 33 & 42 & 40 & 28 \\
\hline Clay $(\%)$ & 24 & 36 & 30 & 23 & 15 & 29 \\
\hline Texture & Sandy clay loam & Clay loam & Clay loam & Loam & Loam & Clay loam \\
\hline
\end{tabular}

paper mulberry plants: 41,53 and 56 plants plot $^{-1}$, respectively. In this site, mixed orchards and grove forests with some para rubber plants were located below and above the study plots. A crown projection diagram of the plants in each plot is shown in Figure 2 .

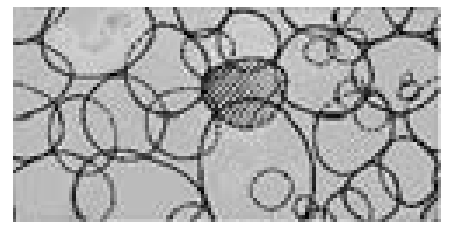

Plot A

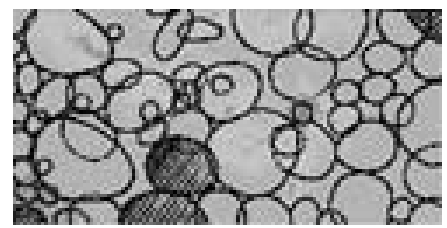

Plot B

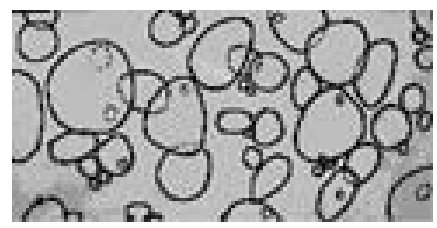

Plot C

Fig. 2. Crown projection diagram of paper mulberry natural stands in Mae Charim site, Nan province

Paper mulberry $\square$ Para rubber

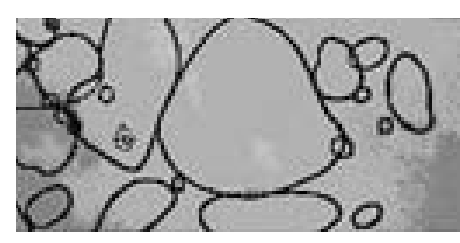

Plot A

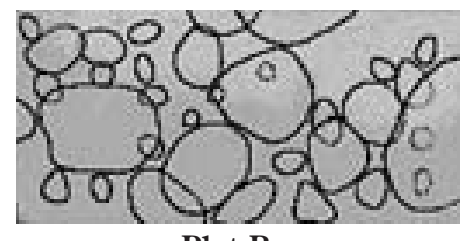

Plot B

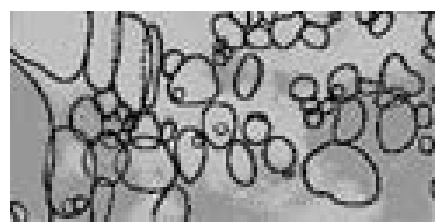

Plot C

Fig. 3. Crown projection diagram of paper mulberry natural stands in Wang chin site, Phrae province 
At Wang chin district, Phrae province, the study site was set along a small canal in an orange orchard. The stand age was 5 years old, with annual harvesting by villagers without any management, similar to the stands in the Mae Charim site. The three plots, A, B and C, had a paper mulberry plant density of 27,35 and 58 plants plot $^{-1}$, respectively. A crown projection diagram of the plants in each plot is shown in Figure 3.

\section{Growth and biomass of paper mulberry in natural stands}

\section{Mae Charim site}

Before the first harvesting, the number of plants in Plot A was lowest (41 plants plot ${ }^{-1}$ ), and had a small variation in size compared to the other two plots. Stem density in three plots illustrated in the same tendency as those in the number of

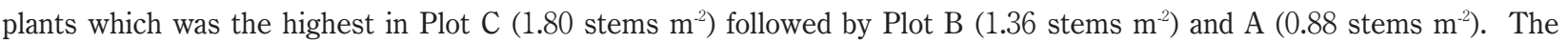
site's average $\mathrm{DBH}$ and height at $\mathrm{M} 1$ was the greatest at $5.6 \mathrm{~cm}$ and $6.21 \mathrm{~m}$, respectively. In Plot $\mathrm{B}$ and $\mathrm{C}$, a wide range of tree size was found, probably due to the existence of para rubber trees that shaded many seedlings and saplings. The average DBH and average height of paper mulberry trees in Plot B were $3.65 \mathrm{~cm}, 3.82 \mathrm{~cm}$, respectively and in Plot C, $5.23 \mathrm{~m}$ and $5.34 \mathrm{~m}$, respectively (Table 3 ).

After harvesting on August 2000, paper mulberry had many coppices in each tree. Likewise, Dietrich (1978) reported that paper mulberry coppices well and throws up abundant root-suckers. Therefore, we found a different number of stems in every plot after harvesting: 1.22, 1.50 and 1.94 stems $\mathrm{m}^{-2}$ in Plot A, B and C, respectively. The average DBH and height during M2 and M3 increased gradually. The average DBH in Plot A was the highest (3.41 and $3.73 \mathrm{~cm}$ during M2 and M3) For biomass yield, the inner bark biomass of paper mulberry in Plot $\mathrm{C}\left(2,238.1\right.$ and 2,420.0 $\mathrm{kg} \mathrm{ha}^{-1}$ for the first and second harvesting) were higher than Plot B (2,233.8 and 2,408.1 $\mathrm{kg} \mathrm{ha}^{-1}$ for the first and second harvesting) and Plot A (1,570.6 and $1,741.2 \mathrm{~kg} \mathrm{ha}^{-1}$ for the first and second harvesting).

Table 3. Plants density, growth and yield of paper mulberry in natural stands in Mae Charim and Wang chin site

\begin{tabular}{|c|c|c|c|c|c|c|}
\hline \multirow{2}{*}{ Analysis topics } & \multicolumn{3}{|c|}{ Mae Charim site } & \multicolumn{3}{|c|}{ Wang chin site } \\
\hline & Plot A & Plot B & Plot C & Plot A & Plot B & Plot C \\
\hline Number of plants (plants plot ${ }^{-1}$ ) & 41 & 53 & 56 & 27 & 35 & 58 \\
\hline Number of stems before the $1^{\text {st }}$ harvesting ( stems $_{\text {plot }}{ }^{-1}$ ) & 44 & 68 & 90 & 34 & 51 & 95 \\
\hline Number of stems after the $1^{\text {st }}$ harvesting (stems plot ${ }^{-1}$ ) & 61 & 75 & 97 & 47 & 73 & 153 \\
\hline Average of stems plant ${ }^{-1}$ & 1.49 & 1.42 & 1.73 & 1.74 & 2.09 & 2.64 \\
\hline Stem density before the $1^{\text {st }}$ harvesting (stems $\mathrm{m}^{-2}$ ) & 0.88 & 1.36 & 1.80 & 0.68 & 1.02 & 1.90 \\
\hline Stem density after the $1^{\text {st }}$ harvesting (stems $\mathrm{m}^{-2}$ ) & 1.22 & 1.50 & 1.94 & 0.94 & 1.46 & 3.06 \\
\hline \multicolumn{7}{|l|}{ Stem $\mathrm{DBH}^{*}(\mathrm{~cm})$} \\
\hline M1 & $5.60^{c}$ & $3.65^{\mathrm{a}}$ & $3.82^{\mathrm{b}}$ & $3.99^{c}$ & $3.61^{\mathrm{b}}$ & $3.37^{\mathrm{a}}$ \\
\hline M2 & $3.41^{c}$ & $2.21^{\mathrm{a}}$ & $2.75^{\mathrm{b}}$ & $1.20^{c}$ & $1.13^{\mathrm{b}}$ & $0.97^{\mathrm{a}}$ \\
\hline M3 & $3.73^{c}$ & $2.51^{\mathrm{a}}$ & $3.00^{\mathrm{b}}$ & $2.06^{c}$ & $1.30^{\mathrm{a}}$ & $1.62^{b}$ \\
\hline Average DBH increment & 0.32 & 0.30 & 0.25 & 0.86 & 0.17 & 0.65 \\
\hline \multicolumn{7}{|l|}{ Stem height* $(\mathrm{m})$} \\
\hline M1 & $6.21^{\mathrm{b}}$ & $5.23^{\mathrm{a}}$ & $5.34^{\mathrm{a}}$ & $10.10^{c}$ & $5.73 b$ & $4.14^{\mathrm{a}}$ \\
\hline M2 & $4.21^{\mathrm{b}}$ & $3.39^{\mathrm{a}}$ & $4.25^{\mathrm{b}}$ & $1.46^{\mathrm{b}}$ & $1.40^{\mathrm{a}}$ & $1.57^{\mathrm{c}}$ \\
\hline M3 & $4.53^{\mathrm{b}}$ & $3.69^{\mathrm{a}}$ & $4.51^{\mathrm{b}}$ & $2.54^{\mathrm{c}}$ & $2.07^{\mathrm{a}}$ & $2.26^{\mathrm{b}}$ \\
\hline Average height increment & 0.32 & 0.30 & 0.26 & 1.08 & 0.67 & 0.69 \\
\hline \multicolumn{7}{|l|}{ Yield of paper mulberry inner bark* $\left(\mathrm{kg} \mathrm{ha}^{-1}\right)$} \\
\hline $1^{\text {st }}$ harvesting & $1570.6^{\mathrm{a}}$ & $2233.8^{\mathrm{b}}$ & $2238.1^{\mathrm{b}}$ & $800.0^{\mathrm{a}}$ & $1360.0^{\mathrm{b}}$ & $2280.0^{c}$ \\
\hline $2^{\text {nd }}$ harvesting & $1741.2^{\mathrm{a}}$ & $2408.1^{\mathrm{b}}$ & $2420.0^{\mathrm{b}}$ & $954.8^{\mathrm{a}}$ & $1153.2^{\mathrm{b}}$ & $2347.6^{c}$ \\
\hline
\end{tabular}

Notes: $\mathrm{M} 1$ = The first measurement before first harvesting, $\mathrm{M} 2=$ The second measurement, M3 = The third measurement

$*$ = signifucant difference at $\mathrm{p}<0.05$, Values within columns followed by superscript are significantly different(95\% confident level; Duncan's test) 


\section{Wang chin's natural stand}

Plot A, B and C showed obvious differences in plant density. Before the first harvesting, the number of plants in Plot A, B

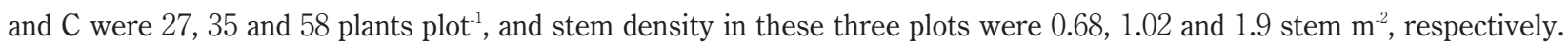

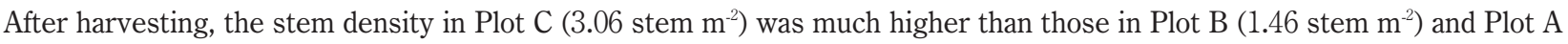
(0.94 stem $\mathrm{m}^{-2}$ ), and higher than the stem density before the first harvesting. Like stem density, the inner bark yield of paper mulberry in Plot $\mathrm{C}$ was higher than that of the other plots during both harvestings: 2,280.0 and 2,347.6 $\mathrm{kg} \mathrm{ha}^{-1}$ in the first and second harvesting, respectively. On the other hand, the inner bark biomass in Plot A was less than Plot B as indicated by the stem density recorded during both harvestings: 800.0 and $954.8 \mathrm{~kg} \mathrm{ha}^{-1}$ in the first and second harvesting in Plot A, and 1,360.0 and 1,153.2 $\mathrm{kg} \mathrm{ha}^{-1}$ in the first and second harvesting in Plot B (Table 3).

As for the soil properties in both study sites, the percentage of sand, silt and clay in almost every plot was not significantly different, except Plot A at Mae Charim had more than $50 \%$ sand, distinguishing it as sandy clay loam. Due to the location of all the sites along a perennially filled canal, soil moisture should not be a limiting factor, which is known to affect the growth of paper mulberry in sandy soil. On the other hand, soils with a high percentage of clay might have some trouble with drainage, possibly affecting the growth of paper mulberry negatively as well. However, the highest percentage of clay was $36 \%$ in Plot B at Mae Charim and this had no negative effect on growth and inner bark biomass.

Soil chemical properties at both sites were greatly different. Organic matter content in Mae Charim soil was high in all plots, while that in Wang chin soil was moderately high only in Plot A. Available P was moderate to high at Mae Charim. On the other hand, the amount of available $\mathrm{P}$ was low in all plots at Wang chin. In addition, the concentrations of exchangeable bases (K, Ca, Mg) in Mae Charim soil were higher than those in Wang chin.

Overall, the soils in the Mae Charim site were more fertile than those in the Wang chin site. This difference may have affected the difference in plant growth and inner bark yield observed between the two sites. Even though the average stem density of the three plots in the Mae Charim site $\left(1.55\right.$ stems $\left.\mathrm{m}^{-2}\right)$ after the first harvesting was smaller than those in the Wang chin site (1.82 stems $\mathrm{m}^{2}$ ), the inner bark yield was higher. Madan \& Sharma (1999) also confirmed that the amount of nutrients in the soil affected the development of new shoots and yield of mulberry (Morus alba) in India. Therefore, soil chemical properties are considered important factors for improving growth and yield of paper mulberry in natural stands. On the other hand, stem density strongly affected inner bark biomass. With increasing density, stand growth and yield increased. Other factors, such as light intensity, could be one of the limiting factors negatively influencing the growth of paper mulberry in natural stands. Veneklass et al. (2002) and Gagnon et al. (2004) also found that the growth and yield of other pioneer species in Moraceae family correlated highly to light intensity, moisture and soil nutrients. Due to crown closure in natural stands of paper mulberry before harvest, paper mulberry trees in Mae Charim had greater crown cover area than those in the Wang chin site (Figure 2 and 3). The crown projection diagram of the Mae Charim site showed that Plot $\mathrm{C}$, which had the highest bark yield, had wider spaces for obtaining light than those in Plot A and B. However, in this study no effect found from this difference.

\section{Diameter distribution in natural stands of paper mulberry}

Among the diameter distribution in M1 before harvesting in Plot A at Mae Charim site, the number of stems in the 1.5-3.5 $\mathrm{cm}$ DBH class, which is the most economical stem size, was the highest (20 stems), while the number of stems in the $<1.5$ cm DBH class was zero (Table 4). Then the diameters of new coppices at M2, the number of stems in the $<1.5 \mathrm{~cm} \mathrm{DBH}$ class was higher than the other DBH classes $(41$ stems) and there were no stems in the large DBH class $(>5.5 \mathrm{~cm})$. During M3, the number of stems in the 1.5-3.5 cm DBH class was the highest (53 stems). On the other hand, the number of stems in the 3.5-5.5 cm DBH class was low and there were no stems in the $>5.5 \mathrm{~cm}$ DBH class (Table 4). Diameter distribution in Plot B and C showed the same tendency as Plot A. The number of stems in the 1.5-3.5 cm DBH class was highest at M1. At $\mathrm{M} 2$, the diameter of the new coppices in the $<1.5 \mathrm{~cm}$ DBH class was greatest. Then at M3, stand growth was distinguished by an increase of the number of stems in the $1.5-3.5 \mathrm{~cm}$ DBH class, and growth of the $<1.5 \mathrm{~cm}$ DBH class exceeded $1.5 \mathrm{~cm}$ of the DBH size. The number of stems in the 1.5-3.5 cm DBH class of Plot B in M2, which were transferred from the $<1.5$ $\mathrm{cm}$ DBH class, was the highest (15 stems) followed by those in Plot A and C (11 and 7 stems, respectively). At M3, the number of stems in the 1.5-3.5 cm DBH class of Plot $\mathrm{C}$ was the highest (67 stems) and the number of stems in the $<1.5 \mathrm{~cm}$ DBH class (63 stems), which are the uneconomical stems, was also much greater in Plot C than in Plot B and A. Therefore, the harvesting period should be extended in order to obtain the economical stems. High stem density, even though it improved inner bark biomass of paper mulberry, negatively affected the growth and may cause a delay in harvesting as well. 
In the Wang chin site, there was a more obvious pattern of diameter distribution than in the Mae Charim site, which had average DBH and height increases. The number of stems in the 1.5-3.5 cm DBH class of Plot A in M2 (4 stems) was the highest followed by those in Plot B and C (3 and 2 stems, respectively). A similar pattern to the Mae Charim site occurred in M3 at the Wang chin site where the number of stems was more in Plot $\mathrm{C}$ than Plot A and B, for both the 1.5-3.5 cm DBH class ( 75 stems) and the $<1.5 \mathrm{~cm}$ DBH class (79 stems). Comparing the two sites, the number of stems in the $1.5-3.5 \mathrm{~cm}$ DBH class in the Wang chin site was lower than those in the Mae Charim site, except in Plot C. This discrepancy may have been caused by low soil fertility that resulted in a lower inner bark biomass. Therefore, soil nutrients may enhance the number of economical stems produced and also increase the biomass yield of paper mulberry. Norgrove \& Hauser (2002) reported that the high timber volume of Cordia alliodora in agrisilvicultural plots was due to enhancing the growth and yield of the intercropped plants with fertilizer application. In this study, there were approximately 1.5 times the timber volume in agrisilvicultural plots of Cordia alliodora than in a mono-silvicultural system, even though the densities were less than half that of a mono-silvicultural system. Due to the high stem density, competition for light, nutrients and soil moisture was severe. Therefore, intensive silvicultural inputs, such as thinning and fertilization, are needed to balance stand development. Also, some studies confirmed that pruning could improve the growth and shape of trees, and has no negative effect on aboveground biomass. In addition, pruning intensifies the increase in biomass partitioning of leaf growth (Montagu et al., 2003; Zeng, 2003).

Table 4. Number of stems of paper mulberry in two study sites (Mae Charim and Wang chin) devided into four DBH classes

\begin{tabular}{|c|c|c|c|c|c|c|c|c|c|c|c|c|c|c|c|c|c|c|}
\hline \multirow{3}{*}{$\begin{array}{c}\text { DBH } \\
\text { Classes } \\
(\mathrm{cm})\end{array}$} & \multicolumn{9}{|c|}{ Mae Charim site } & \multicolumn{9}{|c|}{ Wang chin site } \\
\hline & \multicolumn{3}{|c|}{ Plot A } & \multicolumn{3}{|c|}{ Plot B } & \multicolumn{3}{|c|}{ Plot C } & \multicolumn{3}{|c|}{ Plot A } & \multicolumn{3}{|c|}{ Plot B } & \multicolumn{3}{|c|}{ Plot C } \\
\hline & M1 & M2 & M3 & M1 & M2 & M3 & M1 & M2 & M3 & M1 & M2 & M3 & M1 & M2 & M3 & M1 & M2 & M3 \\
\hline$<1.5$ & 0 & 41 & 23 & 7 & 28 & 37 & 3 & 78 & 63 & 0 & 30 & 13 & 0 & 19 & 37 & 3 & 82 & 79 \\
\hline $1.5-3.5$ & 20 & 11 & 53 & 40 & 15 & 43 & 58 & 7 & 67 & 17 & 4 & 33 & 30 & 3 & 23 & 66 & 2 & 75 \\
\hline $3.5-5.5$ & 15 & 5 & 5 & 15 & 6 & 8 & 16 & 3 & 12 & 10 & 0 & 1 & 15 & 0 & 0 & 11 & 0 & 6 \\
\hline$>5.5$ & 9 & 0 & 0 & 6 & 0 & 0 & 13 & 0 & 0 & 7 & 0 & 0 & 6 & 0 & 0 & 15 & 0 & 0 \\
\hline Total & 44 & 57 & 81 & 68 & 49 & 88 & 90 & 88 & 142 & 34 & 34 & 47 & 51 & 22 & 60 & 95 & 84 & 160 \\
\hline
\end{tabular}

Notes: $\mathrm{M} 1=$ The first measurement before the first harvesting

M2 $=$ The second measurement; 3 months after the first harvesting

M3 = The third measurement; 6 months after the first harvesting

\section{Correlation between inner bark biomass, stem density, growth and soil properties}

According to Pearson's correlation analysis, the inner bark biomass at the first harvest significantly and positively correlated with stem density and significantly and negatively with total height $(\mathrm{p}<0.05)$. Based on these correlations and our visual observation that the longer stems of high plants have thinner bark than those in shorter stems, it can be concluded that total height may negatively affect thickness of paper mulberry inner bark. In the second harvest, the inner bark biomass correlated significantly to stem density and the percentage of clay content in soils $(\mathrm{p}<0.05)$. The concentration of magnesium was significantly correlated to diameter and total height $\left(\mathrm{r}^{2}=0.843\right.$ for diameter and 0.866 for total height at M3 at 0.05 significant level). In addition, there was a significant correlation between diameter and phosphorus concentration ( $\mathrm{r}^{2}$ $=0.941$ and 0.884 at M1 and M3 with 0.01 and 0.05 significant levels, respectively). Xu (2002) also found a relationship between $\mathrm{P}$ concentration and aboveground growth, i.e., trees allocated more biomass to aboveground growth under marginal and adequate P supply. However, this study found that stem density and/or the concentration of phosphorus in soil, can affect an increase in diameter. Further study and more data are needed to clarify this. Based on this study, two equations were obtained by linear regression analysis. Relationships between inner bark yield and important factors are shown below:

$$
\begin{aligned}
& \mathrm{Y}_{1}=2140.974+567.123(\mathrm{SD})-173.258(\mathrm{H}) \text {, Adjusted } \mathrm{R}^{2}=0.87 \\
& \mathrm{Y}_{2}=38.358 \text { (\% Clay) }+752.235(\mathrm{SD})-51.222 \text {, Adjusted } \mathrm{R}^{2}=0.87 \\
& \text { Where, } \mathrm{Y}_{1}=\text { inner bark biomass at the first harvesting, } \\
& \mathrm{Y}_{2}=\text { inner bark biomass at the second harvesting, } \\
& \mathrm{SD}=\text { Stem density }\left(\text { stems } \mathrm{m}^{-2}\right. \text { ), and }
\end{aligned}
$$


$\mathrm{H}=$ Total height $(\mathrm{m})$.

\section{CONCLUSION AND SUGGESTIONS}

Natural stands of paper mulberry are an important source of raw material for paper manufacturing in Thailand. However, quality and quantity control for bast fiber (inner bark fiber) is still limited. This study highlights the important role of soil fertility in enhancing the growth of paper mulberry, while stem density was also shown to have a strong influence on biomass yield. Therefore, intensive management, such as fertilization and weeding at least twice a year, is needed to increase the quality and biomass yield of paper mulberry and decrease nutrient competition as well. Thinning in dense stands is recommended to improve the light intensity and growth rate. On the other hand, replanting in sparse stands will enhance biomass yield and provide more profits for farmers. In this study, Plot B and C in both sites had high paper mulberry bark yields. The stem density in these two plots was 1.5-3.0 stems $\mathrm{m}^{-2}$. Therefore, we recommend that the optimum stem density for paper mulberry in natural stands be 2-3 stems $\mathrm{m}^{-2}$. Among soil nutrients, available phosphorus correlated significantly with the diameter of paper mulberry, however, varied stem density in each plot cannot be ignored, because it was the one of important factors that affected growth and biomass yield of paper mulberry in these stands. Therefore, further study and more data are needed to clarify the role of phosphorus in paper mulberry natural stands.

ACKNOWLEDGEMENTS This study was supported by The Higher Utilization of Forestry and Agriculture Plant Materials in Thailand Project (HUFA Project, 1996-2001) in cooperation with JICA (The Japan International Cooperation Agency) and Kasetsart University, Bangkok Thailand. Moreover, this project received funding from Kasetsart University Research and Development Institute (KURDI) in 1998-2001.

\section{REFERENCES}

Adegbidi, H. G., Jokela, E. J. Comerford, N. B. \& Barros. N. F. 2002. Biomass development for intensively managed loblolly pine plantations growing on Spodosols in the southeastern USA. Forest Ecology and Management 167: 91-102.

Bray, R. H. \& Kurtz, L.T. 1945. Determination of total, organic and available forms of phosphorus in soil. Soil Science 59: 3945.

Brunner, A. 1998. A light model for spatially explicit forest stand models. Forest Ecology and Management 107: $19-46$.

Day, P. R. 1965. Particle fractionation and particle size analysis, pp. 545-567. In: Method of soil analysis. Monograph No. 9. Part I. (Black C. A. ed.) American Society of Agronomy Inc., Madison, Wisconsin.

Dietrich, B. 1978. Indian trees: an account of trees, shrubs, woody climbers, bamboos and Palms. Bishen Siagh Mahendra Pal Singh, Dehra Dun, India. 767 p.

Ford, E. D. 1982. High productivity in a polestage Sitka spruce stand and its relation to canopy structure. [Cited in Kellomaki, S. and H. Strandman. 1995. A model for the structural growth of young Scots pine crowns based on light interception by shoots. Ecological Modelling 80: 237-250.]

Gagnon, L. J., Jokela, E.J. Moser, W.K. \& Huber. D.A. 2004. Characteristics of gaps and natural regeneration in mature longleaf pine flatwoods ecosystems. Forest Ecology and Management 187: 373-380.

Gracia, M. \& Retana, J. 2004. Effect of site quality and shading on sprouting patterns of holm oak coppices. Forest Ecology and Management 188: 39-49.

Kellomaki, S. \& Strandman, H. 1995. A model for the structural growth of young Scots pine crowns based on light interception by shoots. Ecological Modelling 80: 237-250.

Kerr, G. \& Cahalan, C. 2004. A review of site factors affecting the early growth of ash (Fraxinus excelsior L.). Forest Ecology and Management 188: 225-234.

Kilmer, V. J. \& Alexander, L. T. 1949. Method of making mechanical analysis of soils. Soil Science 68: 15-24.

Laatsch, W. 1954. Dynamik d. mitteleuropaischen mineralboden. in Assmann, E. 1970. The principles of forest yield study. Pergamon press. New York, U.S.A.

Land Development Department. 1999. Report of land resource management for economic plants cultivation based on Thailand soil series Vol.2. Ministry of Agriculture, Bangkok, Thailand.

Le Goff, N., Granier, A. Ottorini, J. M. Le Gall, K. Peiffer, M. \& Le Tacon, F. 1995. In Kerr, G. and C. Cahalan. 2004. A 
review of site factors affecting the early growth of ash (Fraxinus excelsior L.). Forest Ecology and Management 188: 225234.

Le Goff, N. and J. M. Ottorini. 1996. [Cited in Kerr, G. \& Cahalan. C. 2004. A review of site factors affecting the early growth of ash (Fraxinus excelsior L.). Forest Ecology and Management 188: 225-234.

Madan, M. \& Sharma, S. 1999. Biomass yield of hybrid varieties of mulberry in a non-moriculture area. Biomass and Bioenergy 17: 427-433.

Matthew, P. J. 1990. Ethnobotanic, and origins of Broussonetia papyrifera in Polynesia: an essay on tapa prehistory. Oceanic culture history: essays in honour of Roger Green New Zealand Journal of Archaeology special publication: 117-132.

Mongkolsook, Y., Tanasombat, M. Nimla-or, W. Rattana, R. Wattanawikkit, P. \& Wongwan, P. 2001. Selection and production of Paper mulberry varieties for pulp and paper industry. pp.281-286. Proceeding of the international symposium on paper mulberry and hand-made papers for rural development. Bangkok, Thailand.

Montagu, K. D., Kearney, D. E. \& Smith, R. G. B. 2003. The biology and silviculture of pruning planted eucalypts for clear wood production-a review. Forest Ecology and management 179: 1-13.

Norgrove, L. \& Hauser, S. 2002. Measured growth and tree biomass estimates of terminalia ivorensis in the 3 years after thinning to different stand densities in an agrisilvicultural system in southern Cameroon. Forest Ecology and Management 166: 261-270.

Onyekwelu, C. J. 2004. Above-ground biomass production and biomass equations for even-aged Gmelina arborea (ROXB) plantations in south-western Nigeria. Biomass and Bioenergy 26: 39-46.

Ottorini, J. M., Le Goff, N. \& Cluzeau, C. 1996. [Cited in Kerr, G. \& Cahalan. C. 2004. A review of site factors affecting the early growth of ash (Fraxinus excelsior L.). Forest Ecology and Management 188: 225-234.

Phengklai, C. \& Khamsai, S. 1985. Some non-timber species of Thailand. Thai. For. Bull. (Bot.) 15: 48-108.

Peech, M. 1945. Determination of exchangeable cation and exchange capacity of soil rapid micromethod utilizing centrifuge and spectrophotometer. Soil Science 59: 25-28.

Pratt, P. E. 1965. Potassium, pp. 1022-1030. In: Method of soil analysis. Monograph No. 9. Part II. (Black C. A. ed.) American Society of Agronomy Inc., Madison, Wisconsin.

Shujauddin, N. \& Nohan Kumar, B. 2003. Ailanthus triphysa at different densities and fertilizer regimes in Kerala, India: growth, yield, nutrient use efficiency and nutrient export through harvest. Forest Ecology and Management 180: 135151.

Thammincha, S \& Tanasombat, M. 2001. Role of Saa fiber to rural development. pp.1-2. Proceeding of the international symposium on paper mulberry and hand-made papers for rural development. Bangkok, Thailand.

Udomchoke, V., Mongkolsook, Y. Anapanurak, W. Tanasombat, M. \& Kesjinda, K. 2001. The environmental conditions on natural distribution of paper mulberry in Thailand. pp.79-90. Proceeding of the international symposium on paper mulberry and hand-made papers for rural development. Bangkok, Thailand.

USDA. 1999. Soil taxonomy, a basic system of soil classification for making and interpreting soil surveys (2 ed). Natural Resources Conservation Service, United States Department of Agriculture, USA. 869 p.

Veneklaas, E. J., Santos Silva, M. P. R. M. \& den Ouden, F. 2002. Determinants of growth rate in Ficus benjamina L. compared to related faster-growing woody and herbaceous species. Scientia Horticulture 93: 75-84.

Walkley, A. \& Black, C. A. 1934. An examination of Degtjareff method for determining soil organic matter: a proposed modification of the chromic acid titration method. Soil Science 37: 29-35.

Xu, D., Dell, B. Malajczuk, N. \& Gong, M. 2002. Effects of P fertilization on productivity and nutrient accumulation in a Eucalyptus grandis $\mathrm{x}$ E. urophylla plantation in southern China. Forest Ecology and management 161: 89-100.

Zeng, B. 2003. Aboveground biomass partitioning and leaf development of Chinese subtropical trees following pruning. Forest Ecology and Management 173: 135-144. 